\title{
The biocompatibility and mechanical properties of plasma sprayed zirconia coated abutment
}

\author{
Zhengfei Huang ${ }^{1,2}$, Zhifeng Wang ${ }^{1,3}$, Kaifeng Yin ${ }^{4}$, Chuanhua $\mathrm{Li}^{2}$, Meihua Guo ${ }^{2}$, Jing Lan ${ }^{1,2 *}$ \\ ${ }^{1}$ Shandong Provincial Key Laboratory of Oral Tissue Regeneration, School of Stomatology, Shandong University, Jinan, Shandong \\ Province, China \\ ${ }^{2}$ Department of Prosthodontics, School of Stomatology, Shandong University, Jinan, Shandong Province, China \\ ${ }^{3}$ Department of Pediatric Dentistry, School of Stomatology, Shandong University, Jinan, Shandong Province, China \\ ${ }^{4}$ Department of Orthodontics, Herman Ostrow School of Dentistry, University of Southern California, Los Angeles, CA, USA
}

\begin{abstract}
PURPOSE. The aim of this study was to evaluate the clinical performance and reliability of plasma sprayed nanostructured zirconia (NSZ) coating. MATERIALS AND METHODS. This study consisted of three areas of analysis: (1) Mechanical property: surface roughness of NSZ coating and bond strength between NSZ coating and titanium specimens were measured, and the microstructure of bonding interface was also observed by scanning election microscope (SEM). (2) Biocompatibility: hemolysis tests, cell proliferation tests, and rat subcutaneous implant test were conducted to evaluate the biocompatibility of NSZ coating. (3) Mechanical compatibility: fracture and artificial aging tests were performed to measure the mechanical compatibility of NSZcoated titanium abutments. RESULTS. In the mechanical study, $400 \mu \mathrm{m}$ thick NSZ coatings had the highest bond strength $(71.22 \pm 1.02 \mathrm{MPa})$, and a compact transition layer could be observed. In addition, NSZ coating showed excellent biocompatibility in both hemolysis tests and cell proliferation tests. In subcutaneous implant test, NSZcoated plates showed similar inflammation elimination and fibrous tissue formation processes with that of titanium specimens. Regarding fatigue tests, all NSZ-coated abutments survived in the five-year fatigue test and showed sufficient fracture strength (407.65-663.7 N) for incisor teeth. CONCLUSION. In this study, the plasmasprayed NSZ-coated titanium abutments presented sufficient fracture strength and biocompatibility, and it was demonstrated that plasma spray was a reliable method to prepare high-quality zirconia coating. [J Adv Prosthodont 2020;12:157-66]
\end{abstract}

KEYWORDS: Abutment; Nanostructured zirconia coating; Plasma spray; Biocompatibility; Mechanical property

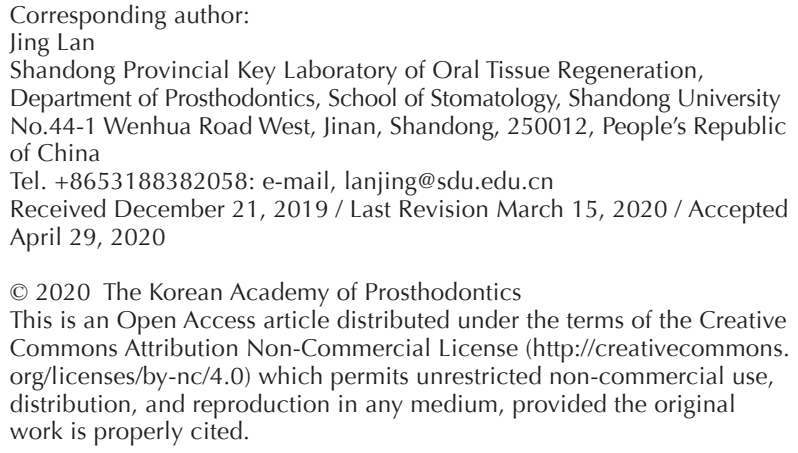

This is an Open Access article distributed under the terms of the Creative Commons Attribution Non-Commercial License (http://creativecommons. org/licenses/by-nc/4.0) which permits unrestricted non-commercial use, distribution, and reproduction in any medium, provided the original work is properly cited.

Zhengfei Huang and Zhifeng Wang are co-first authors.

The work was funded by grants 81671025 (Beijing, China) from National Natural Science Foundation of China, 2015GSF118186 (Jinan, China) and ZR2018ZB0105 (Ji'nan, China) from Foundation of Department of Science and Technology of Shandong province.

\section{INTRODUCTION}

In clinical dentistry, implant supported crown and denture restoration are commonly accepted treatments in managing partially and completely edentulous patients. Titanium is the most widely applied material for dental implant over the last few decades given its excellent biocompatibility, great mechanical properties and corrosion resistance. ${ }^{1}$ However, compromised esthetics is often related to the exposure of the metal color of titanium abutments, especially in patients with thin mucosa or gingival recession. ${ }^{2}$ Moreover, titanium dental abutment may generate a galvanic effect after contacting sali$\mathrm{va}^{3}{ }^{3}$ and titanium wear particles can lead to tumor necrosis factor (TNF) alpha-mediated inflammatory responses. ${ }^{4}$

Zirconia is a type of biomaterial with adequate mechani- 
cal properties and biocompatibility for medical use, such as artificial joints in orthopedics. ${ }^{5}$ In implant dentistry, yttriumstabilized tetragonal zirconia polycrystals (Y-TZP) are the main material of zirconia abutment given good esthetics and excellent biocompatibility. ${ }^{6}$ Moreover, given the "stressinduced phase transformation toughening" characteristic of Y-TZP, zirconia coating presented improved mechanical properties. ${ }^{7}$ The introduction of zirconia abutment successfully improved the esthetic outcome of implant-supported restoration, but the high brittle properties of zirconia led to low fracture resistance. ${ }^{8}$ In addition, the poor friction compatibility between zirconia ceramic abutment and titanium implant would cause excessive wear and result in the formation of microleakages and bacterial invasion. ${ }^{9}$ To combine good toughness of titanium with excellent surface properties of zirconia, the zirconia coating was applied on titanium abutment. However, titanium is easily oxidized, and the non-adhesive $\mathrm{TiO}_{2}$ layer would decrease the bond strength between zirconia coating and titanium abutment, ${ }^{10}$ which impeded the clinical application of zirconia-coated abutment.

The plasma spray technique is a flexible coating preparation technique that is quick and stable ${ }^{11}$; moreover, various parameters, such as porosity, crystallization rates and chemical component, are easy to control. Given these features, the plasma spray has been widely used in various types of technical areas. ${ }^{12}$ In this study, the plasma spray technique will be employed to improve the bond strength between zirconia coating and titanium abutment. We hypothesize that plasma spraying is a reliable technique to prepare zirconia coating on titanium substrate, and that the plasma-sprayed zirconia coatings possess good mechanical properties, biocompatibility, and mechanical compatibility.

\section{MATERIALS AND METHODS}

Medical grade titanium rods (Ti-6AL-4V, length $70 \mathrm{~mm}$, diameter $8 \mathrm{~mm}$ ) were prepared (Baoji Titanium Industry Company Limited, Baoji, China). All titanium specimens were polished, rinsed and sandblasted with $\mathrm{Al}_{2} \mathrm{O}_{3}$ particles (particle size $110 \mu \mathrm{m})$. Nanosized (70 - $110 \mathrm{~nm}$ ) yttria-stabilized tetragonal zirconia pelleting powders (Y-TZP, Lida Hi-Tech Special Material Co., Ltd., Changshu, Jiangsu, China) were spray-dried and heat-treated to form circularshaped particles $(15-45 \mu \mathrm{m})$. The shaped NSZ particles were plasma sprayed onto the surface of the titanium implant under low vacuum using the SM-80 Plasma spraying system (Xiuma Spraying Machinery Co., Ltd., Shanghai, China) with arc voltage: $82 \mathrm{~V}$, arc current $500 \mathrm{~A}$, powder feed rate $40 \mathrm{~g} / \mathrm{min}$, spray distance $70 \mathrm{~mm}$. In addition, compressed air was employed to cool down the titanium specimen and maintain its temperature at approximately $200^{\circ} \mathrm{C}$ during the whole spraying period.

To select the thickness of NSZ coating with the best mechanical properties, a series of mechanical tests were conducted on the five groups of specimens (100, 200, 300, 400 , and $500 \mu \mathrm{m})$. First, the surface roughness of NSZcoated titanium rods (23 specimens per group) was mea- sured using a mobile roughness-measuring instrument (MarSurf PS1, Mahr, Göttingen, Germany). For each specimen, the measurement of $\mathrm{Ra}$ was conducted thrice on six surface areas. Second, three specimens were randomly selected from each group for NSZ-titanium interface analysis using scanning electron microscope (SEM, JSM-6380 LA, JOEL USA Inc., Peabody, MA, USA). The protocol of sample preparation for SEM analysis was described previously. ${ }^{13}$ Third, pull-off test was conducted on the remaining twenty specimens in each group using a tensile tester (LDS5 Digital Display Tensile tester, Lunjie, Shanghai, China). Uncoated titanium rods (length $70 \mathrm{~mm}$, diameter $8 \mathrm{~mm}$ ) were glued to the coating surface of NSZ-coated titanium rods with epoxy resin (ADBEST E-7, Shanghai Research Institute of Synthetic Resin, Shanghai, China) and cured at $100^{\circ} \mathrm{C}$ for 3 hours. The rate of extension was set at 0.5 $\mathrm{mm} / \mathrm{min}$, and NSZ-titanium interfacial bond strength $(\mathrm{P}$, $\mathrm{MPa}$ ) was calculated using formula: $\mathrm{P}=\mathrm{F} / \mathrm{S}$ ( $\mathrm{F}$ : the value of force recorded when NSZ coating layer is detached from titanium base, N; S: the area of NSZ-titanium interface, in $\mathrm{mm}^{2}$ ). Finally, the microhardness was obtained for all specimens by measuring the indentations that were produced by a standard Vickers hardness indenter (pyramid-shaped diamond indenter) at $200 \mathrm{~g}$ for $20 \mathrm{~s}$ (HVS-1000 microhardness tester, Huayin Instrument, Laizhou, Shandong, China). The average values of surface roughness ( $\mathrm{Ra}, \mathrm{n}=23$ ), NSZtitanium interfacial bond strength $(\mathrm{MPa}, \mathrm{n}=20)$ and microhardness $(\mathrm{HV}, \mathrm{n}=20)$ were recorded for each specimen tested. ANOVA and LSD-t tests were used to detect the significant differences among groups (SPSS 20.0, $\alpha=.05$ ).

Titanium plates were prepared (Ti-6AL-4V, $7 \mathrm{~mm} \times 5$ mm, Baoji Titanium Industry Company Limited, Baoji, Shanxi, China) to investigate the biocompatibility of the NSZ coating. The thickness of the NSZ coating was controlled as the best sample in mechanical tests.

To prepare hemolysis assay, fresh rabbit blood was diluted with $0.9 \%$ saline (Life Technologies, Grand Island, NY, USA) at 1:20 and kept at $4^{\circ} \mathrm{C}$. Three experimental groups were set up as follows: (1) Positive control, $10 \mathrm{~mL}$ distilled water $+0.2 \mathrm{~mL}$ diluted rabbit blood; (2) Negative control, $10 \mathrm{~mL} 0.9 \%$ saline $+0.2 \mathrm{~mL}$ diluted rabbit blood; and (3) Sample, autoclaved NSZ-coated titanium plate $+10 \mathrm{~mL}$ $0.9 \%$ saline $+0.2 \mathrm{~mL}$ diluted rabbit blood. All specimens were incubated at $37^{\circ} \mathrm{C}$ for $60 \mathrm{~min}$ and then centrifuged at $750 \mathrm{~g}$ for $5 \mathrm{~min}$. The optical density (OD) of supernatant was measured at $545 \mathrm{~nm}$ using Genequant Pro UV/Vis Spectrometer (Biochrom, Cambridge, England). The hemolysis ratio was calculated using the formula: hemolysis ratio $=(\mathrm{OD}$ of sample $-\mathrm{OD}$ of negative control $) /(\mathrm{OD}$ of positive control - OD of negative control) $\times 100 \%$.

To test the cytotoxicity of NSZ coating, L929 cells (Catalog\# 85011425, Sigma Aldrich, St. Louis, MO, USA) were seeded into 6 -well (1 mL per well) and 96 -well $(0.1 \mathrm{~mL}$ per well) cell culture plates at $5.0 \times 10^{4}$ cells $/ \mathrm{mL}$ and incubated under regular conditions for $24 \mathrm{~h}$. Then, the culture medium in 96-well cell culture plates was replaced by (1) DMEM (Dulbecco's Modified Eagle's Medium, Gibco ${ }^{\circledR}$ Life 
Technologies, Grand Island, NY, USA) with $0.64 \%$ phenol (positive control), (2) DMEM (negative control), (3) sample extract (incubating autoclaved NSZ-coated titanium plates in DMEM for $72 \mathrm{~h}$ ), and (4) DMEM (empty control group, no cells in wells). For cells cultured in 6-well plates, images of cells were taken under phase-contrast microscopy after incubation for $24 \mathrm{~h}, 48 \mathrm{~h}$, and $72 \mathrm{~h}$. At the same time points, culture medium was removed from 96-well plates, and $100 \mu \mathrm{l}$ Cell Counting Kit-8 (CCK-8) assay solution (Catalog\# CK0401, Dojindo Molecular Technologies, Shanghai, China) was added. The OD values were measured at $450 \mathrm{~nm}$ using the iMark $^{\mathrm{TM}}$ Microplate Absorbance Reader (Bio-Rad, Life Science, Hercules, CA, USA), and the relative growth rate (RGR, \%) was calculated using the formula: RGR $=(\mathrm{OD}$ of sample or positive control - OD of empty control) / (OD of negative control - OD of empty control) $\times 100 \%$. According to cytotoxicity grades of US Pharmacopoeia (USP 34), the cytotoxicity grades were rated as $0,1,2,3,4$ corresponding to $100,80-99,50-79,30-49,0-29$ RGR (\%), respectively.

In subcutaneous implant assay, all vertebrate animal manipulation was performed in accordance with institutional and national guidelines. This animal experiment was approved by Institutional Animal Care and Use Committee at Shandong University (Grant No. GD201615). As the hosts for NSZ-coated titanium plates, 24 8-week-old male Wistar rats $(180-200 \mathrm{~g})$ were purchased from Shandong University Laboratory Animal Center. Before implantation, the animals were anesthetized with intraperitoneal injection of $10 \%$ chloral hydrate $(0.3 \mathrm{~mL} / 100 \mathrm{~g})$. The NSZ-coated titanium plates were implanted subcutaneously $1 \mathrm{~cm}$ away from the dorsolumbar vertebrae followed by subcutaneous injection of penicillin $\mathrm{G}(160000 \mathrm{U})$. The animals were randomly divided into 6 groups $(n=4)$, which were sacrificed at 3 days, 1 week, 2 weeks, 4 weeks, 8 weeks, and 12 weeks after operation. Heart perfusion with $4 \%$ paraformaldehyde was used to fix the animals, and the soft tissues surrounding the implant area were harvested. Paraffin-embedded tissue blocks were sectioned at a thickness of $5 \mu \mathrm{m}$ and were subject to $H \& E$ staining.

This study complied with the EQUATOR guidelines.

The parameters of Ankylos ${ }^{\circledR}$ one-piece dental implants (DENTSPLY Implants China, Beijing, China) were obtained using the LPX-250 laser scanner (Roland, Tokyo, Japan) as to prepare the specimens for fatigue test and fracture strength test of NSZ-coated abutments. According to the measurements, medical grade titanium rods (Norman Metal Products, Qingdao, Shandong, China) were employed to fabricate four types of nonthreaded one-piece dental implants $(\mathrm{n}=12)$, which differed in the diameter of abutment neck by (1) $2.6 \mathrm{~mm}$, (2) $2.0 \mathrm{~mm}$, (3) $1.8 \mathrm{~mm}$, and (4) $1.6 \mathrm{~mm}$ (the thinnest part of the tapered abutment, white arrow in Fig. 1A).

NSZ was the plasma spayed onto the abutments in groups B, C, and D with a thickness of $300 \mu \mathrm{m}, 400 \mu \mathrm{m}$, and $500 \mu \mathrm{m}$, respectively. No coatings were prepared on specimens in group A, which were used as the control group. Thus, the diameter of abutments was $2.6 \mathrm{~mm}$ in all

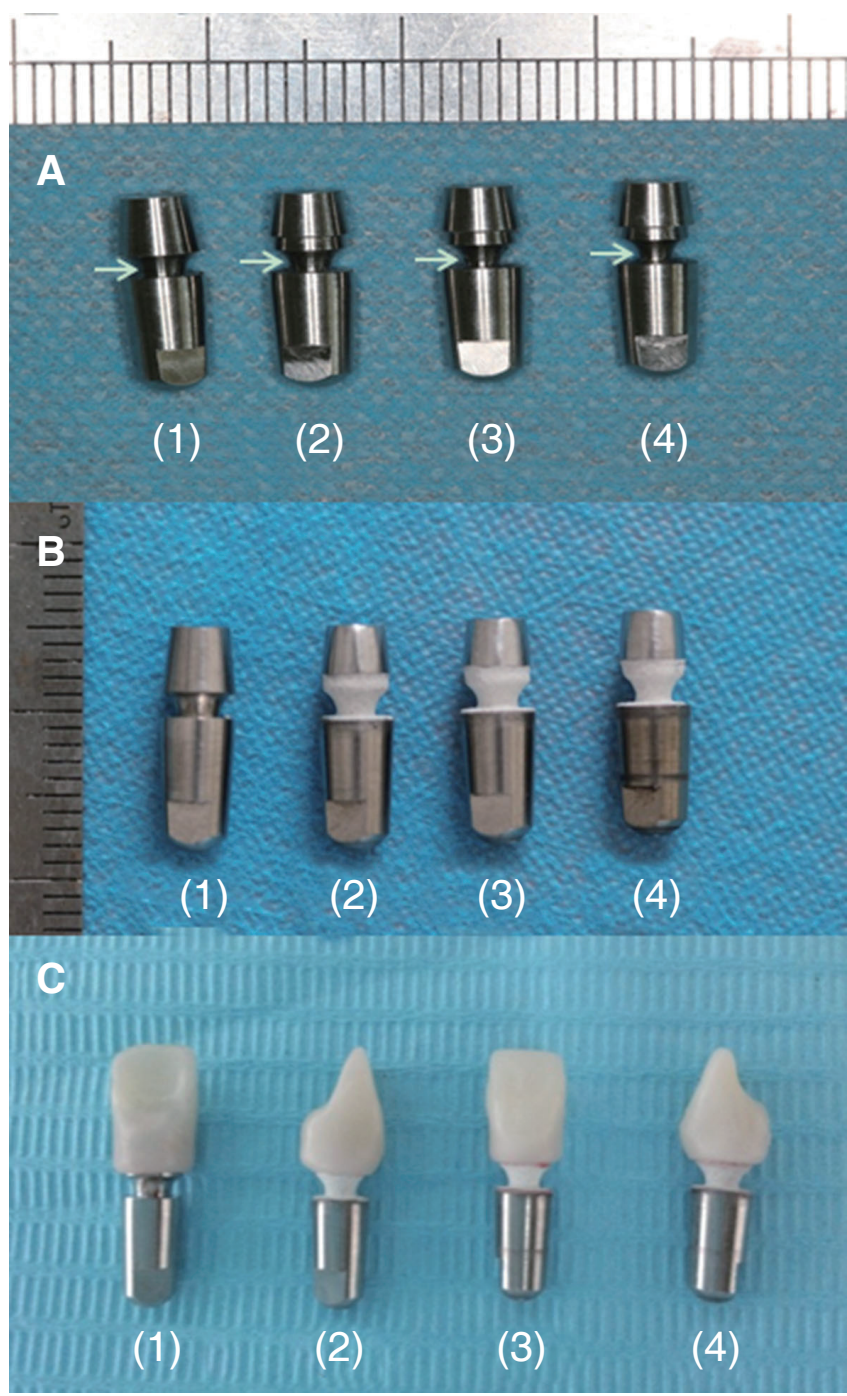

Fig. 1. Implants for fatigue test and fracture strength test. (A) Implants with different abutment neck (white arrow) diameters were prepared: (1) $2.6 \mathrm{~mm}$, (2) $2.0 \mathrm{~mm}$, (3) 1.8 $\mathrm{mm}$, and (4) $1.6 \mathrm{~mm}$. (B) NSZ coatings were prepared for all abutments. (C) Lava zirconia crowns were bonded on all abutments.

groups (Fig. 1B). Lava zirconia crowns in the shape of maxillary central incisors (Yangziiing Dental Instrument, Beijing, China) were bonded by RelyX Unicem Self-adhesive Universal Resin Cement (3M, St. Paul, MN, USA) (Fig. 1C). In half of the specimens in each group, a portion of the implant (with exposed abutment and crown) was wrapped by a $0.2-\mathrm{mm}$ polytetrafluoroethylene membrane and embedded in self-cure polymethylmethacrylate. The fatigue test was conducted using a Thermocycling and Mechanical Loading Chewing Simulator (Peking University, Beijing, China). The specimens were oriented at an angle of $135^{\circ}$ to the horizontal plane to simulate the $45^{\circ}$ buccal-lingual inclination of upper central incisors. ${ }^{14}$ The 'chewing' force was 
applied to the lingual surface of crowns $2 \mathrm{~mm}$ from the incisal edge ( $45 \mathrm{~N}, 5 \mathrm{~Hz}, 1200000$ cycles). The 'oral temperature' alternated between $5{ }^{\circ} \mathrm{C}$ and $55^{\circ} \mathrm{C}$ every $60 \mathrm{~s}$ for 10000 cycles. The accelerated aging process of dental implant was equivalent to clinical use for five years. ${ }^{15}$ Subsequently, a fracture strength test was conducted on both fatigued and unfatigued specimens (AGS-X Series Electromechanical Precision Universal Tester, Shimadzu Scientific Instruments, Tokyo, Japan). The workpiece holder was placed $2 \mathrm{~mm}$ below abutment-implant connection, and the crosshead moved at a rate of $1.5 \mathrm{~mm} / \mathrm{min}$ and formed an angle of $45^{\circ}$ with the long axis of the implant.

The fracture site and maximum loading force (fracture strength, N) were recorded for each specimen. The intergroup significant differences in fracture strength were detected using two-tail Kruskal-Wallis tests and MannWhitney U tests (SPSS 20.0, $\alpha=.05$ ). Two-tail Wilcoxon signed-rank tests were used for comparison between fatigued and unfatigued specimens (SPSS 20.0, $\alpha=.05$ ).

\section{RESULTS}

There was no statistically significant difference in surface roughness among the five groups $(\mathrm{n}=23, P>.05)$ (Fig. $2 \mathrm{~A}$ ), and the average Ra values ranged from $0.175 \mu \mathrm{m}$ to $0.287 \mu \mathrm{m}$. In SEM analysis, compared with other groups, $400 \mu \mathrm{m}$ thick NSZ coating showed a more compact and even distributed transition layer along the NSZ-Ti interface. Micropores or microcracks were minimally detected in both the NSZ coating layer and NSZ-Ti interface (Fig. 3). The transition layer of NSZ coating in $300 \mu \mathrm{m}$ and $500 \mu \mathrm{m}$ (Fig. $3 \mathrm{C}, 3 \mathrm{E})$ groups were not as even as that observed in the 400 $\mu \mathrm{m}$ group, and microcracks could be found. NSZ coatings in the $100 \mu \mathrm{m}$ and $200 \mu \mathrm{m}$ groups exhibited porous structures, and the interfaces were clearly delineated without a transition layer (Fig. 3A, 3B).

In pull-off test (Fig. 2B), specimens in the $400 \mu \mathrm{m}$ group have the highest bond strength at $71.22 \pm 1.02 \mathrm{MPa}$, whereas the $100 \mu \mathrm{m}$ group presented the minimum value $(44.76 \pm 2.26 \mathrm{MPa})$. According to the retrieved specimens after pull-off test, the $400 \mu \mathrm{m}$ thick NSZ coating was relatively intact (Fig. 4D), and the detachment site was the interface between coatings and resin adhesives. In other groups, the detachment sites were within the NSZ coatings (Fig. 4A, 4B, 4C, 4E).

The microhardness of NSZ coatings ranged from 636.26 $\pm 5.09 \mathrm{HV}$ (in the $100 \mu \mathrm{m}$ group) to $662.21 \pm 4.96 \mathrm{HV}$ (in the $400 \mu \mathrm{m}$ group) (Fig. $2 \mathrm{C}$, ANOVA, $\mathrm{n}=20, P<.01$ ). The microhardness of the $300 \mu \mathrm{m}, 400 \mu \mathrm{m}$, and $500 \mu \mathrm{m}$ groups were significantly higher than those of the $100 \mu \mathrm{m}$ and 200 $\mu \mathrm{m}$ groups (LSD-t, $\mathrm{n}=20, P<.05$ ), and no statistical significance was noted among the three groups (Fig. 2C, ANOVA, $\mathrm{n}=20, P>.05)$.

In the hemolysis assay, the $\mathrm{OD}$ value of positive-control centrifuge tubes was $0.84 \pm 0.011$, indicating that hemolytic response occurred. In contrast, serum-like supernatant was obtained from the negative control and sample groups, and
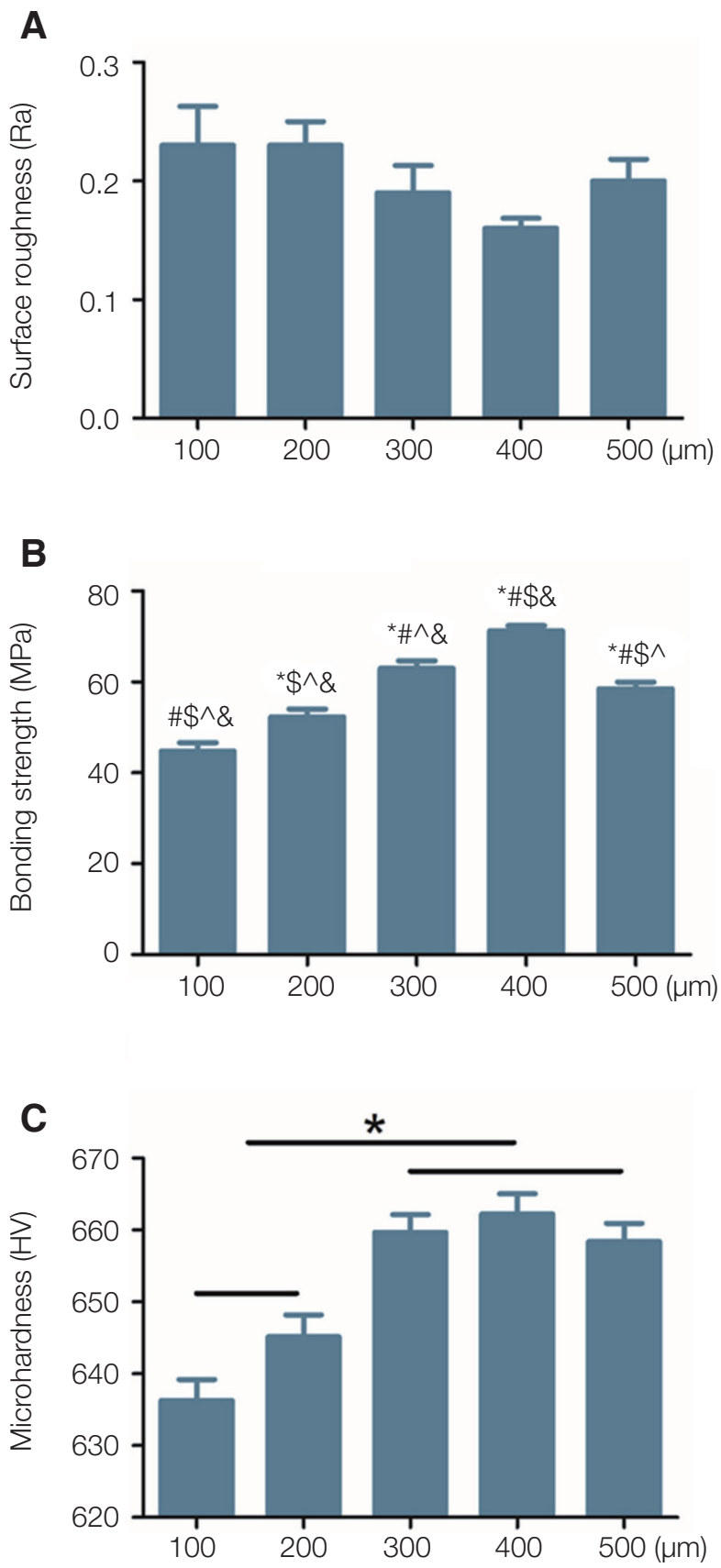

Fig. 2. Mechanical properties of NSZ coating. (A) Surface roughness of different groups $(P>.05)$. (B) NSZ-titanium bonding strength of five groups. ${ }^{*}$ indicates statistical difference versus $100 \mu \mathrm{m}$ group with $P<.05$, \# indicates statistical difference versus $200 \mu \mathrm{m}$ group with $P<.05, \$$ indicated statistical difference versus $300 \mu \mathrm{m}$ group with $P<.05, \wedge$ indicated statistical difference versus $400 \mu \mathrm{m}$ group with $P<.05, \&$ indicated statistical difference versus $500 \mu \mathrm{m}$ group with $P<.05$. (C) Microhardness of NSZ coatings. There is no difference in microhardness between 100 and $200 \mu \mathrm{m}$ groups $(P>.05), 300,400$, and $500 \mu \mathrm{m}$ groups also show similar microhardness $(P>$ $.05)$. The microhardness of 300,400 , and $500 \mu \mathrm{m}$ groups is higher than that of 100 , and $200 \mu \mathrm{m}$ groups $(P<.05)$. 

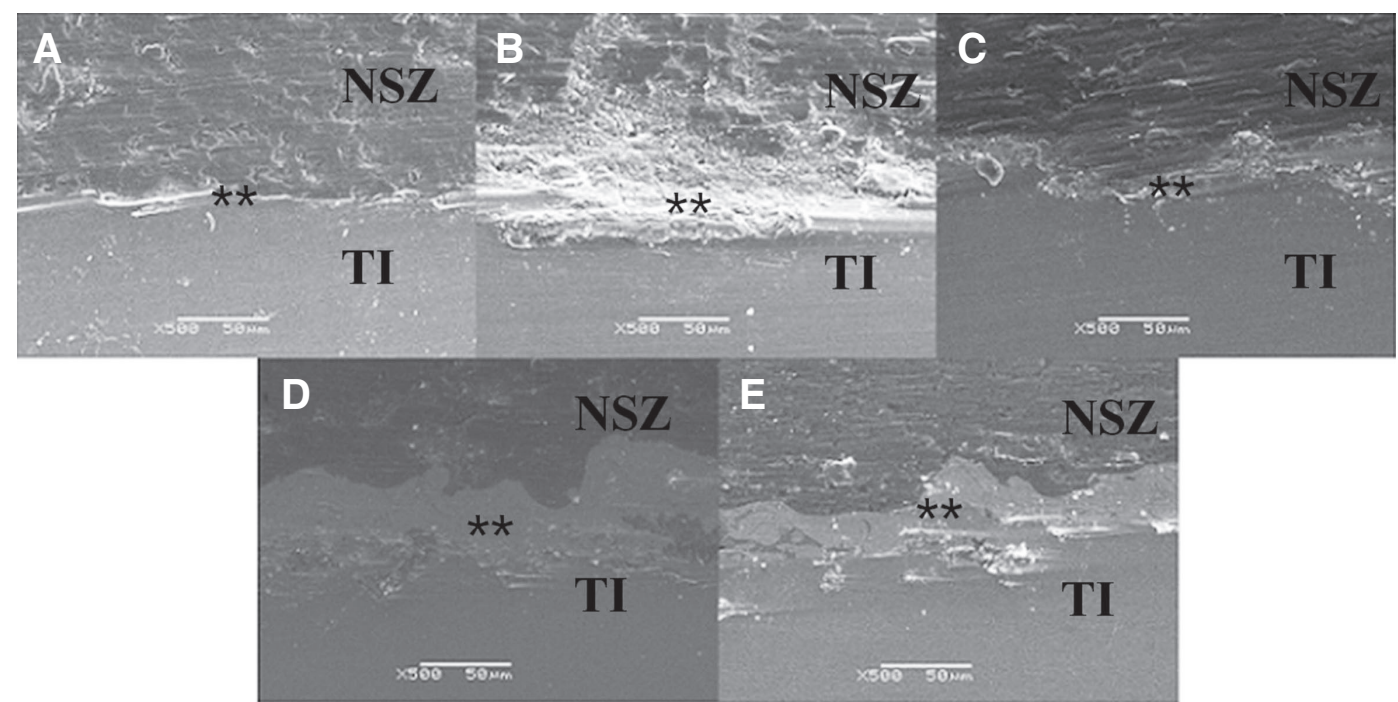

Fig. 3. SEM analysis of NSZ-titanium interface. Nanostructured zirconia (NSZ); Titanium (Ti). The interfaces of $100 \mu \mathrm{m}$ (A), $200 \mu \mathrm{m}(\mathrm{B}), 300 \mu \mathrm{m}(\mathrm{C}), 400 \mu \mathrm{m}(\mathrm{D})$, and $500 \mu \mathrm{m}$ (E) NSZ coatings were presented (magnification $\AA \sim 200)$. NSZtitanium interface was labeled by $* *$.

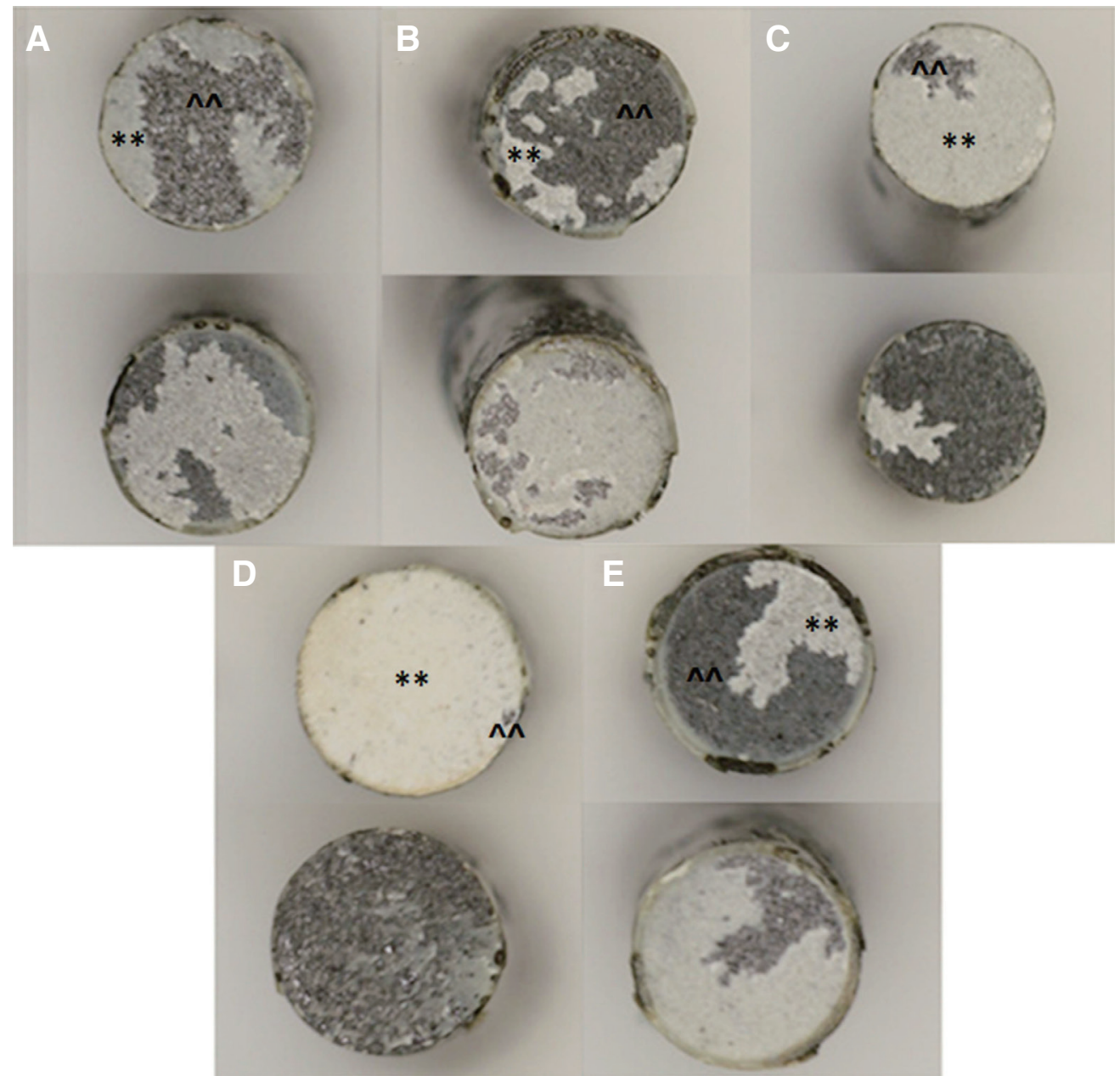

Fig. 4. The fractured surfaces of specimens in pull-off test. The fractured surfaces of $100 \mu \mathrm{m}(\mathrm{A}), 200 \mu \mathrm{m}(\mathrm{B}), 300 \mu \mathrm{m}$ (C), $400 \mu \mathrm{m}$ (D), and $500 \mu \mathrm{m}$ (E) NSZ coatings were presented. The upper were NSZ coated titanium specimens and the nether were titanium specimens which were glued onto. The detachment between coating and glue was labeled by ${ }^{* *}$, the detachment between coating and substrate was labeled by $\wedge \wedge$. 
the average OD values were $0.019 \pm 0.002$ and $0.025 \pm$ 0.002 , respectively (Fig. 5A). The calculated hemolysis ratio of specimens (NSZ-coated titanium plates) was $0.731 \%$.

In cell proliferation and cytotoxicity assays, the morphology and growth rate of L929 cells in the negative control were similar to those observed in specimen group from $24 \mathrm{~h}$ to $72 \mathrm{~h}$ (Fig. 5B-6, 9, 12). In contrast, a majority of the cells in the positive control group were detached from the dish bottom by the end of $72 \mathrm{~h}$ (Fig. 5B-11). In the whole period of time, the OD values in the specimen group were similar to those in the negative control group (Fig. 5C), and RGRs were all greater than $90 \%$, which corresponded to cytotoxicity grade 1 (Fig. 5D).

Tissue responses to NSZ-coated titanium plates were evaluated by subcutaneous implant test on rats. At post-surgery 3 days, the subcutaneous tissue surrounding the NSZcoated implant exhibited minor inflammatory reactions with a scatter of neutrophils and lymphocytes, and an absence of hyperemia, fibrous sac formation, and tissue necrosis (Fig. 5E-2). At 1 week, subcutaneous tissue was infiltrated by more inflammatory cells, which consisted mainly of neutrophils and lymphocytes (Fig. 5E-4). At 2 weeks, the inflammatory reaction mitigated, which was evidenced by less lymphocytes infiltration, and the fibrous sac started to form (Fig. 5E-6). At 4 weeks, with the appearance of large amount of collagen fibers, the fibrous sac increased extensively in thickness and compactness (Fig. 5E-8). At 8 weeks, foreign body granuloma was not observed and inflammatory cells, including neutrophils, lymphocytes and macrophages, could be barely detected (Fig. 5E-10). At 12 weeks, the NSZ-coated implant was wrapped by highly condensed fibrous tissue with fewer cell components (Fig. 5E-12). There were no signs of degradation of NSZ coating layer in all stages of healing period (Fig. 5E-2, 4, 6, 8, 10, 12). Similar histological findings were obtained from the group of titanium implant without NSZ coating layer (Fig. 5E-1, $3,5,7,9,11)$.

In fatigue test and fracture strength test, all specimens remained intact after cyclic loading with temperature changes in the fatigue test, and no detachment or cracking of the NSZ coating was found. In the following fracture strength test, all specimens fractured at the site of the neck abutment, which is the thinnest part of abutments. Regarding fracture strength $(\mathrm{N})$, no difference could be found between fatigued and unfatigued specimens (Wilcoxon signed-rank test, $\mathrm{n}=6, P>.05$ ) (Fig. 6A), but there were significant differences across the four groups for both fatigued specimens and unfatigued specimens (Kruskal-Wallis test, $\mathrm{n}=6, P<$ .05) (Fig. 6B, 6C). The abutments without zirconia coating presented the highest fracture strength at $785.5 \pm 66.58 \mathrm{~N}$, while the specimens in $500 \mu \mathrm{m}$ group had the minimum value at $475.67 \pm 68.02 \mathrm{~N}$ (Mann-Whitney $\mathrm{U}$ test, $\mathrm{n}=6, \mathrm{P}<$ $.05)$.

\section{DISCUSSION}

In this study, the aim was to prepare zirconia coating on titanium abutment using plasma spray technique, improving the bond strength between zirconia coating and titanium substrate, and that the hypothesis was that plasma-sprayed zirconia coatings possess good mechanical properties, biocompatibility, and mechanical compatibility. The biocompatibility of plasma-sprayed NSZ coating was evaluated by hemolysis, cell proliferation, cytotoxicity, and subcutaneous implant assay. The average hemolysis ratio of NSZ-coated implants was $0.731 \%$. This value was within the $5 \%$ limit for acceptable blood compatibility of biomaterials. ${ }^{16} \mathrm{In}$ addition, because the RGR value of fibroblast-like cells cultured in NSZ coating extract was greater than $90 \%$, the cytotoxicity of NSZ coating was rated as grade 1 . In the subcutaneous implant study, the NSZ-coated titanium plates were encapsulated by a thin layer of fibrous tissue by the end of the 12-week healing period, and no wear products of NSZ coating were observed in histological analysis. Collectively, these findings were consistent with the previous conclusion regarding the biocompatibility of zirconia. ${ }^{6}$

Regarding the mechanical properties, bond strength and coating intensity were analyzed. Bond strength is the coating-substrate adhesion, while coating intensity is the ability that coating keeps itself intact. In pull-off test, $400 \mu \mathrm{m}$ thick NSZ coatings showed the highest coating intensity and bond strength, which were reflected in the intactness and no detachment, respectively. In 100 and $200 \mu \mathrm{m}$ groups, the majority of coating was detached and it indicated the poor bond strength between coating and substrate. In addition, the detachment in these two groups was scattered and extensive, indicating the poor coating intensity in these two groups. While in 300 and $500 \mu \mathrm{m}$ groups, the detached parts had clear boundary and centered on a certain area. This indicated the relative higher coating intensity of 300 and $500 \mu \mathrm{m}$ groups than those of 100 and $200 \mu \mathrm{m}$ groups.

Comparing the exposed fracture surface among different groups, both the coating intensity and bond strength were low when the NSZ coating was thin (100 and $200 \mu \mathrm{m})$. With the increase in coating thickness (300 and $400 \mu \mathrm{m}$ ), the coating exhibited higher bond strength and coating intensity, and only small pieces of exfoliation were observed. When the coating thickness was thicker $(500 \mu \mathrm{m})$, the coating intensity increased but the bond strength decreased. Thus, to prepare a high-quality zirconia coating, bond strength and coating intensity were all imperative, but it was difficult to balance these two factors while simultaneously maintaining high bond strength and improving coating intensity. In this study, $400 \mu \mathrm{m}$ represents an ideal thickness for plasma-sprayed NSZ coating under the abovementioned parameters.

In SEM, the transition layer could be found in the 300, 400 , and $500 \mu \mathrm{m}$ groups. In particular, in the $400 \mu \mathrm{m}$ groups, there was a compact transition layer between NSZ coating and titanium substrate, while a clear boundary and micro-cracks were found at the NSZ-Ti interface in the 100 and $200 \mu \mathrm{m}$ groups. Taking the same spraying conditions and materials into consideration, the possible reason for the different interface may be that the thicker coating possessed 
A
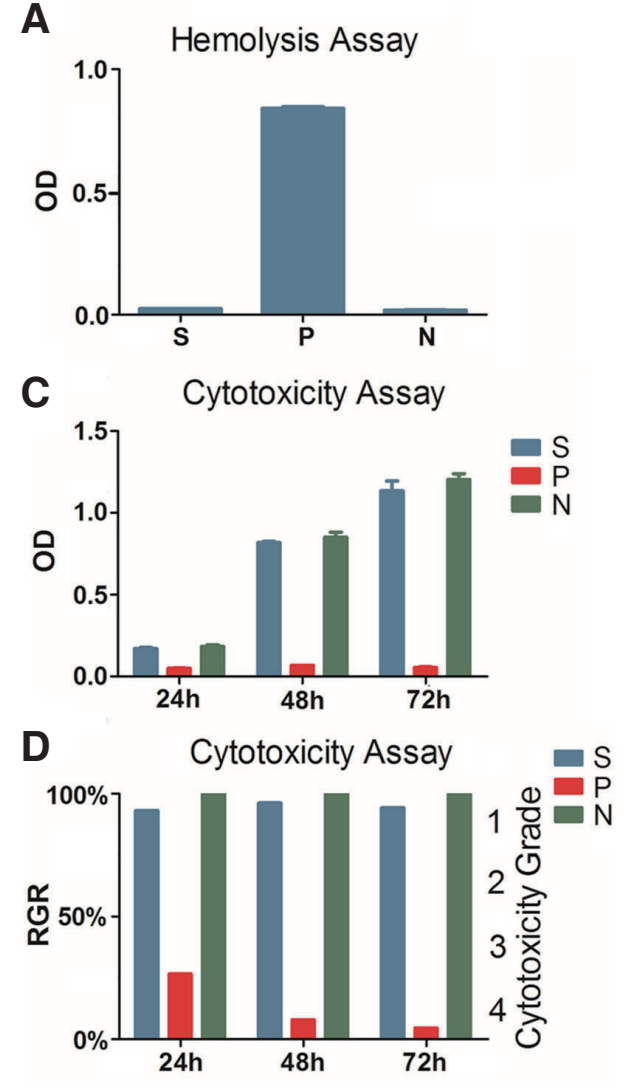

B

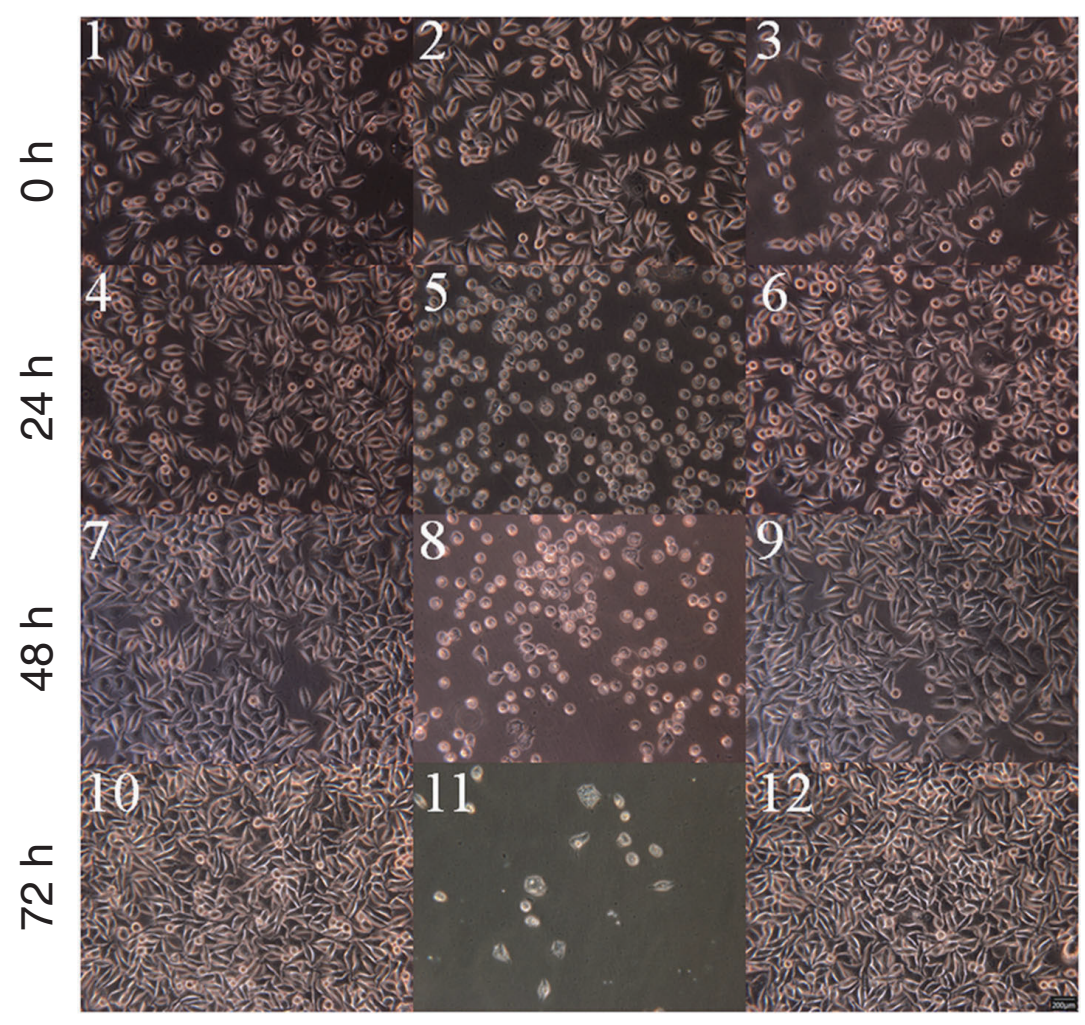

E

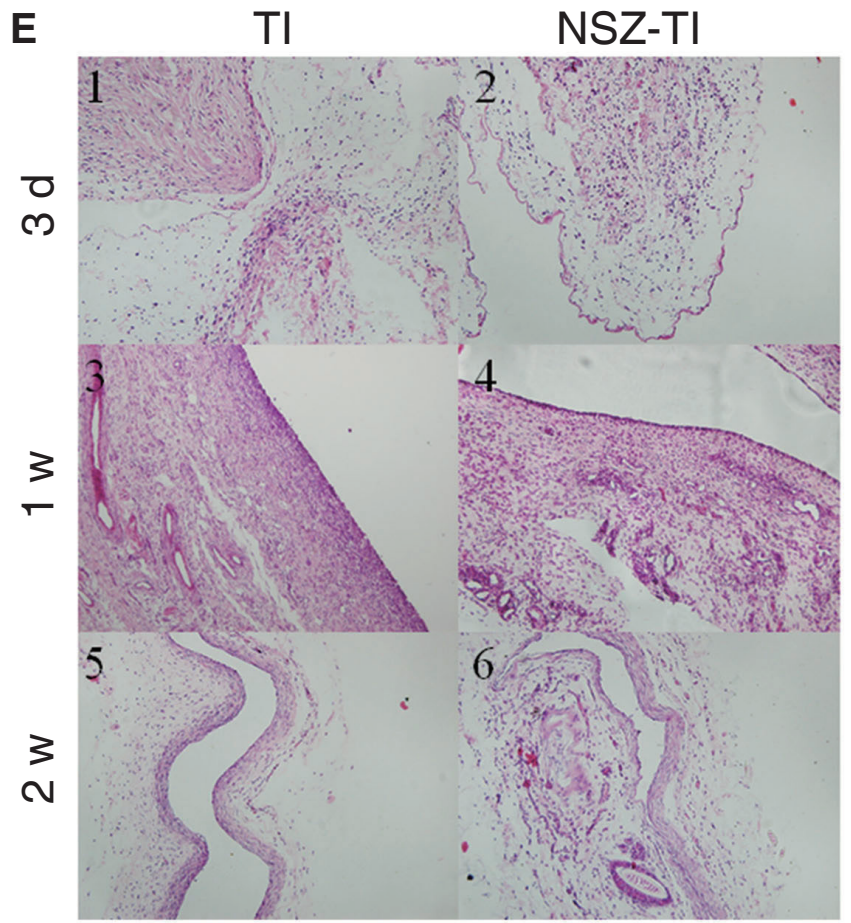

S

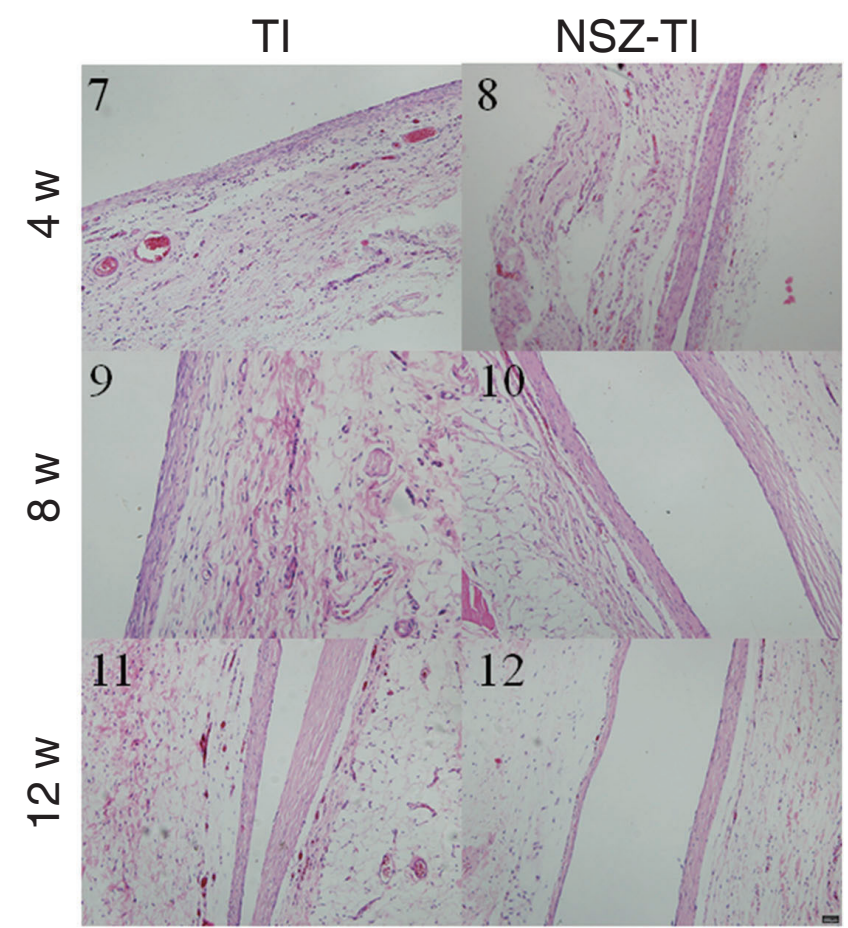

Fig. 5. Biocompatibility study of NSZ coating. Sample group (S); Positive group (P); Negative group (N); Optical density (OD); Relative growth rate (RGR); Titanium plate (Ti); NSZ coated titanium plate (NSZ-Ti). (A) Hemolysis assay. (B) Cell proliferation and cytotoxicity assay (magnification $\times 40$ ). (C) The OD values in cytotoxicity assay. (D) The RGRs in cytotoxicity assay. (E) Histological analysis of tissue around implants (magnification $\times 10$ ). 
A

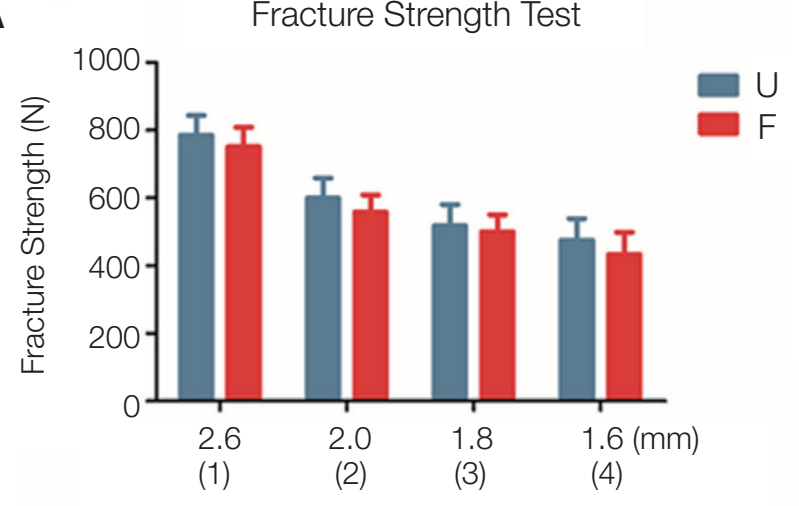

B
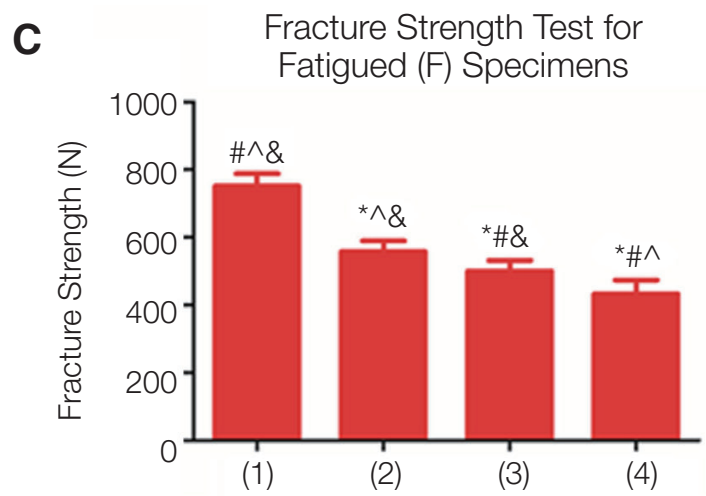

Fig. 6. Fracture strength test for NSZ-coated titanium abutment. (A) No statistically significant difference in fracture strength $(\mathrm{N})$ was found between fatigued and unfatigued specimens. (B) and (C) In both fatigued and unfatigued specimens, there were statistically significant differences in fracture strength could be found between different groups. ${ }^{*}$ indicates statistical difference versus $100 \mu \mathrm{m}$ group with $P<.05$, \# indicates statistical difference versus $200 \mu \mathrm{m}$ group with $P<.05, \$$ indicated statistical difference versus $300 \mu \mathrm{m}$ group with $P<.05, \wedge$ indicated statistical difference versus $400 \mu \mathrm{m}$ group with $P<.05, \&$ indicated statistical difference versus $500 \mu \mathrm{m}$ group with $P<.05$. more heat, guaranteeing a sufficient melting and flattening degree of zirconia particles. However, rapid heat reduction would occur in the thinner group, which leads to insufficient melting of zirconia particles and poor coating quality.

Specific information regarding the processes of preparing NSZ coating should be mentioned. The size of zirconia particles is imperative to the morphology and quality of zirconia coating. ${ }^{17}$ Compared with ordinary microsized zirconia particle, agglomerating nanosized $(70-110 \mathrm{~nm})$ zirconia particles to the microscale could simultaneously maintain the high melting and flattening degree and increase the momentum. In addition, the non-melting area could be avoided in ordinary microsized zirconia particles, and the uniformity of zirconia coating could be improved. In addition, compressed air was employed to cool the titanium substrate and maintain its temperature at approximately $200^{\circ} \mathrm{C}$ in the whole spraying period, decreasing the formation of the non-adhesive oxide layer, which was recognized as the main reason leading to the low bond strength between zirconia coating and titanium substrate in traditional technology. ${ }^{10}$ Compared with previous studies ${ }^{18,19}$ that employed the plasma spray technique and zirconia particles to prepare zirconia coating on the titanium substrate, it could be concluded that plasma spray parameters, category of zirconia particles, and coating thickness were all closely related to coating quality and bond strength. In this study, optimized plasma spray parameters were employed, including increased voltage and powder feed rate and decreased current and spray distance. Moreover, Y-TZP was used as a raw material that which contained $3 \%$ mol $\mathrm{Y}_{2} \mathrm{O}_{3}$ as a stabilizer, maintaining zirconia in a tetragonal phase $\left(\mathrm{t}-\mathrm{ZrO}_{2}\right)$ at room temperature but not a monoclinic phase $\left(\mathrm{m}-\mathrm{ZrO}_{2}\right)$. When force was imposed on the zirconia coating, the transformation from $\mathrm{t}-\mathrm{ZrO}_{2}$ to $\mathrm{m}-\mathrm{ZrO}_{2}$ synchronized with 3 - 5\% volume expansion and $1-7 \%$ shear strain, inhibiting the expansion of cracks to some degree and improving the fracture strength of Y-TZP coating. ${ }^{7}$ Undoubtedly, the characteristic of "stress-induced phase transformation toughening" improved the coating intensity of NSZ coating and enabled good performance in the abutment test. ${ }^{20-22}$

In the fatigue test, the durability of the NSZ coating was evaluated, and all the NSZ-coated abutments survived the 'five-year' cyclic loading of lateral mastication forces without coating detachment or cracking. No significant difference was observed between fatigued and unfatigued specimens in fracture strengths. The minimum value of fracture strength exceeded $400 \mathrm{~N}$, which was greater than the documented bite force of incisor teeth $(90-370 \mathrm{~N})^{23}$ and indicated that NSZ-coated abutment was promisingly applicable in clinical use. With the optimized technological parameters and raw material, there was a significant improvement in fracture strength compared with previous studies, which reported that the fracture strength of one-piece zirconia abutments after thermocycling and fatigue test was $232.1 \pm$ $29.8 \mathrm{~N}^{24}$ The same test was performed on two-piece zirconia abutments with a titanium base, and the fracture strength was $377.6 \mathrm{~N} .^{25}$ 
Another finding to be noted was that the NSZ-coated abutments were less resistant than pure titanium abutments in terms of lateral fracture force. The fracture strengths decreased significantly with the reduction of the diameters of titanium abutments, which suggested the pivotal role of the titanium base in designing dental implants.

There are also some limitations in this study. First, in this study, with the given raw material and plasma spraying parameters, $400 \mu \mathrm{m}$ zirconia coating showed the best mechanical properties, but the technical parameters and the processing of raw material could be further optimized as to improve the intensity of NSZ-coating and its bond strength with titanium substrate. It has been found in this study that the fracture strength of NSZ-coated abutment decreased significantly with the decrease of the diameter of titanium abutment. Therefore, improving the intensity of zirconia coating and decreasing the required thickness are imperative for increasing the fracture strength of NSZ-coated abutment. Second, a Thermocycling and Mechanical Loading Chewing Simulator was used for five-year fatigue test and achieved 100\% survival rate. However, in clinic, patients would expect high success rate at a longer time, like 10-years or 20-years. So, the success rate at longer time should be tested in further study. In addition, maximal cycling number would be another plausible indicator to test the durability of NSZ-coated abutment except fracture strength. Third, the bacteria adhesion and surface characteristics of zirconia coating are the factors that need to be investigated in further study as to avoid peri-implantitis and to ensure the durability of implants. In this study, the surface roughness of the polished NSZ coating reached a minimum of 0.13 $\mu \mathrm{m}$ and it was reported that the nanoscale surface roughness $(<214 \mathrm{~nm})$ could affect the formation of oral biofilm ${ }^{26}$ by reducing bacterial adhesion. ${ }^{27}$ The antibacterial effect of the NSZ coating might also benefit its application in abutments.

\section{CONCLUSION}

In this study, the plasma-sprayed NSZ-coated titanium abutments presented sufficient fracture strength and biocompatibility, and it was demonstrated that plasma spray was a reliable method to prepare high-quality Y-TZP coating. In further studies, the parameters of the plasma spray technique will be optimized to achieve better mechanical compatibility between NSZ coating and titanium substrate.

\section{ORCID}

Zhengfei Huang https://orcid.org/0000-0002-5656-2446

Kaifeng Yin bttps://orcid.org/0000-0003-3562-1934

Chuanhua Li https://orcid.org/0000-0002-5753-2089

Meihua Guo bttps://orcid.org/0000-0003-2975-7261

Jing Lan https://orcid.org/0000-0002-9732-5172

\section{REFERENCES}

1. Long M, Rack HJ. Titanium alloys in total joint replacement-a materials science perspective. Biomaterials 1998;19:1621-39.

2. Wadhwani CP, O’Brien R, Kattadiyil MT, Chung KH. Laboratory technique for coloring titanium abutments to improve esthetics. J Prosthet Dent 2016;115:409-11.

3. Lee JJ, Song KY, Ahn SG, Choi JY, Seo JM, Park JM. Evaluation of effect of galvanic corrosion between nickel-chromium metal and titanium on ion release and cell toxicity. J Adv Prosthodont 2015;7:172-7.

4. Guo H, Zhang J, Hao S, Jin Q. Adenovirus-mediated small interfering RNA targeting tumor necrosis factor- $\alpha$ inhibits titanium particle-induced osteoclastogenesis and bone resorption. Int J Mol Med 2013;32:296-306.

5. Zhu W, Sugano N, Pezzotti G. Nondestructive inspection of phase transformation in zirconia-containing hip joints by confocal Raman spectroscopy. J Biomed Opt 2013;18:127002.

6. Brunot-Gohin C, Duval JL, Verbeke S, Belanger K, Pezron I, Kugel G, Laurent-Maquin D, Gangloff S, Egles C. Biocompatibility study of lithium disilicate and zirconium oxide ceramics for esthetic dental abutments. J Periodontal Implant Sci 2016;46:362-71.

7. Kuo C, Shen Y, Yen F, Cheng H, Hung I, Wen S, Wang M, Stacke M. Phase transformation behavior of $3 \mathrm{~mol} \%$ yttria partially-stabilized ZrO2 (3Y-PSZ) precursor powder by an isothermal method. Ceramics International 2014;40:3243-51.

8. Mühlemann S, Truninger TC, Stawarczyk B, Hämmerle CH, Sailer I. Bending moments of zirconia and titanium implant abutments supporting all-ceramic crowns after aging. Clin Oral Implants Res 2014;25:74-81.

9. D'Ercole S, Tripodi D, Marzo G, Bernardi S, Continenza MA, Piattelli A, Iaculli F, Mummolo S. Microleakage of bacteria in different implant-abutment assemblies: an in vitro study. J Appl Biomater Funct Mater 2015;13:e174-80.

10. Marcelli E, Costantino ML, Villa T, Bagnoli P, Zannoli R, Corazza I, Cercenelli L. Effect of intermediate $\mathrm{ZrO} 2-\mathrm{CaO}$ coatings deposited by cold thermal spraying on the titaniumporcelain bond in dental restorations. J Prosthet Dent 2014; 112:1201-11.

11. Vardelle A, Moreau C, Themelis N, Chazelas C. A perspective on plasma spray technology. Plasma Chem Plasma Process 2015;35:491-509.

12. Prasauskas T, Matulevicius J, Kliucininkas L, Krugly E, Valincius V, Martuzevicius D. Filter media properties of mineral fibres produced by plasma spray. Environ Technol 2016;37:1315-24.

13. Guo M, Wang Z, Fan X, Bian Y, Wang T, Zhu L, Lan J. Kgp, $\operatorname{rgpA}$, and $\operatorname{rgpB} \mathrm{DNA}$ vaccines induce antibody responses in experimental peri-implantitis. J Periodontol 2014;85:1575-81.

14. Reill MI, Rosentritt M, Naumann M, Handel G. Influence of core material on fracture resistance and marginal adaptation of restored root filled teeth. Int Endod J 2008;41:424-30.

15. Kohal RJ, Finke HC, Klaus G. Stability of prototype twopiece zirconia and titanium implants after artificial aging: an in vitro pilot study. Clin Implant Dent Relat Res 2009;11:323-9.

16. Amarnath LP, Srinivas A, Ramamurthi A. In vitro hemocompatibility testing of UV-modified hyaluronan hydrogels. 
Biomaterials 2006;27:1416-24.

17. Khor KA, Gu YW, Pan D, Cheang P. Microstructure and mechanical properties of plasma sprayed HA/YSZ/Ti-6Al-4V composite coatings. Biomaterials 2004;25:4009-17.

18. Zhang Y, Chen L, Shi M, Zhai D, Zhu H, Chang J, Wu C, Zheng X, Yin J. Mesoporous bioactive glass nanolayer-modified zirconia coatings on Ti-6Al-4V with improved in vitro bioactivity. Int J Appl Glass Sci 2016;7:216-28.

19. Jemata A, Ghazali MJ, Razali M, Otsuka Y, Rajabi A. Effects of $\mathrm{TiO} 2$ on microstructural, mechanical properties and in-vitro bioactivity of plasma sprayed yttria stabilised zirconia coatings for dental application. Ceram Int 2018;44:4271-81.

20. Wongkamhaeng K, Dawson DV, Holloway JA, Denry I. Effect of surface modification on in-depth transformations and flexural strength of zirconia ceramics. J Prosthodont 2019;28:e364-75.

21. Guan SH, Zhang XJ, Liu ZP. Energy landscape of zirconia phase transitions. J Am Chem Soc 2015;137:8010-3.

22. Pittayachawan P, McDonald A, Young A, Knowles JC. Flexural strength, fatigue life, and stress-induced phase transformation study of Y-TZP dental ceramic. J Biomed Mater Res B Appl Biomater 2009;88:366-77.

23. Tortopidis D, Lyons MF, Baxendale RH, Gilmour WH. The variability of bite force measurement between sessions, in different positions within the dental arch. J Oral Rehabil 1998; 25:681-6.

24. Gehrke P, Johannson D, Fischer C, Stawarczyk B, Beuer F. In vitro fatigue and fracture resistance of one- and two-piece CAD/CAM zirconia implant abutments. Int J Oral Maxillofac Implants 2015;30:546-54.

25. Alsahhaf A, Spies BC, Vach K, Kohal RJ. Fracture resistance of zirconia-based implant abutments after artificial long-term aging. J Mech Behav Biomed Mater 2017;66:224-32.

26. Xing R, Lyngstadaas SP, Ellingsen JE, Taxt-Lamolle S, Haugen HJ. The influence of surface nanoroughness, texture and chemistry of TiZr implant abutment on oral biofilm accumulation. Clin Oral Implants Res 2015;26:649-56.

27. Herbst D, Dullabh H, Sykes L, Vorster C. Evaluation of surface characteristics of titanium and cobalt chromium implant abutment materials. SADJ 2013;68:350, 352-6. 